\title{
Mathematical modelling as a virtual learning environment for teacher education programs
}

\author{
Modelación matemática como ambiente virtual de aprendizaje \\ para los programas de formación de profesores
}

\author{
Milton Rosa* \\ (iD) : https://orcid.org/0000-0002-5190-3862 \\ Daniel Clark Orey ${ }^{* *}$ \\ (iD) : https://orcid.org/0000-0002-8567-034X
}

Tipo de Artículo: Informes de Investigación y ensayos inéditos

Doi: 10.17533/udea.unipluri.19.2.04

Cómo citar este artículo:

Rosa, M., \& Orey, D. C. (2019). Mathematical Modelling as a Virtual Learning Environment for teacher education programs. Uni-pluriversidad, 19(2), 80-102. doi: 10.17533/udea.unipluri.19.2.04

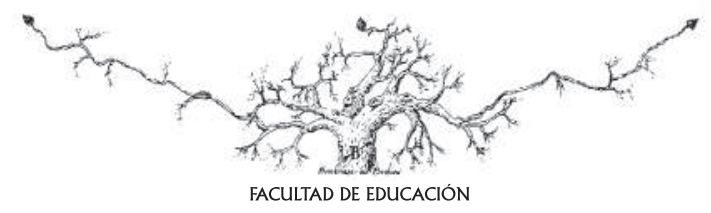

Recibido: 2019-09-14 • Aprobado: 2019-12-09

\footnotetext{
* Universidade Federal de Ouro Preto

E-mail: milrosa@hotmail.com

** Universidade Federal de Ouro Preto

E-mail: oreydc@gmail.com
} 


\begin{abstract}
This study was developed with 76 students enrolled in a teacher education program in Mathematics, which is part of the Brazilian Open University System, at the Universidade Federal de Ouro Preto. It was conducted during the second semester of 2017, in 5 (five) educational centres (polos) located in the states of São Paulo and Minas Gerais, in Brazil. This research was performed according to methodological procedures used in case studies, by covering the collection and data analysis. Methodological procedures used in this study enabled the critical and reflectpive interpretation of the results through the elaboration of categories that emerged from qualitative data collected during the development of the fieldwork. The main objective of this study was the proposition of mathematical modelling as a virtual learning environment (VLE) that favours the development of a critical view of the reality and the reflection of students in solving problems that they face daily, by developing modelling projects by applying technological tools available in the Moodle platform. Through these projects, students problematized, contextualized, and investigated problems they developed in their projects in the VLE. As well, they elaborated questions that aimed to seek, collect, select, organize, and handle the information that allowed them to critically reflect about the role of mathematics in society.
\end{abstract}

Keywords: Distance Education, Mathematical Modelling, Modelling Projects, Virtual Learning Environment, Teacher Education Program.

\title{
Resumen
}

Este estudio fue desarrollado con 76 estudiantes matriculados en un programa de formación docente en Matemáticas del Sistema Universitario Abierto de Brasil, de la Universidade Federal de Ouro Preto (UFOP), durante el segundo semestre de 2017, en 5 (cinco) centros educativos (polos) ubicados en los estados de Minas Gerais y São Paulo, en Brasil. Esta investigación se realizó de acuerdo con los procedimientos metodológicos utilizados en los estudios de casos, cubriendo la recopilación y el análisis de datos. Los procedimientos metodológicos usados en este estudio permitieron la interpretación crítica y reflexiva de los resultados mediante la elaboración de categorías que surgieron de los datos cualitativos recopilados durante el desarrollo de este trabajo de campo. El objetivo principal de este estudio fue la propuesta de modelación matemática como un ambiente virtual de aprendizaje (AVA) que favorece el desarrollo de la crítica de la realidad y la reflexión de los estudiantes para resolver los problemas que enfrentan en su vida diaria, mediante el desarrollo de proyectos de modelación con la aplicación de herramientas tecnológicas disponibles en la plataforma Moodle. A través de estos proyectos, los estudiantes problematizaron, contextualizaron e 
investigaron problemas que desarrollaron en sus proyectos en el AVA. Además, los estudiantes prepararon preguntas destinadas a buscar, recopilar, seleccionar, organizar y manejar la información que les permitió reflexionar críticamente sobre el papel de las matemáticas en la sociedad.

Palabras clave: Educación a distancia, Modelación matemática, Proyectos de modelación, Ambiente virtual de aprendizaje, Programa de formación docente. 


\section{INITIAL REMARKS}

Currently, mathematical modelling presents several definitions, conceptualizations, perspectives, and dimensions that are discussed and debated in congresses, conferences, seminars, and national and international events (Kaiser \& Sriraman, 2006). One of these conceptualizations is that modelling can be characterized as a learning environment in teacher education programs in Mathematics that provides students with the necessary mechanisms for the development of their citizenship in a responsible and critical way (Rosa \& Orey, 2016).

According to this context, Barbosa (2006) states that modelling can be defined as a learning environment in which students are invited to inquire and/or investigate through mathematics, problems, situations, and phenomena originating in other areas of reality. Thus, mathematical modelling is considered as a learning environment that aims to facilitate the investigation of problems from reality through the elaboration of contextualized pedagogical activities. These activities encourage students to develop mathematical knowledge in order to solve problems present in their own reality.

Mathematical modelling as a virtual learning environment enables the development of critical reflections on mathematical aspects involved in themes that students chose to study. It provides them with technological mechanisms that enable the advancement of their citizenship in a responsible way. Consequently, this process is enhanced by the use of technological resources found in mathematics teacher education programs in distance learning modality (Rosa \& Orey, 2018).
Thus, Virtual Learning Environments (VLEs) also allow students to develop critical and reflective discussions about the role of mathematics in society because issues regarding the development of their modelling projects posted in the VLE contained important information that assisted them to develop data analysis and interpretation of the findings of their mathematical models (Freitas, 2016).

In this regard, López Dávila (2015) states that VLEs enable the "achievement of research objectives and the development of products or programs to be implemented in virtual environments supplied with the right scientific foundations and full correspondence and interrelation between educational requirements and technological possibilities in the virtual world" (p. 62).

Therefore, VLEs provide technological resources that guide students to collaboratively advance the elaboration of mathematical modelling projects that help them to solve problems in a constructive and responsible way towards society, which is developed disregarding time, space, and place (Rosa \& Orey, 2016). Because human activity is mediated through the application of technological resources (Brown, 2015), the use of VLEs transforms mathematics and mathematical thinking. In this perspective, Borba (2005) states that technologies function as mediators in the production of knowledge and in the development of communication despite of the influence of other factors that outline these processes. 
In this context, Rosa and Orey (2018) affirm that Virtual Learning Environments serve as democratic educational environments that allow for the development of collaborative learning and dialogical interactions. It enables the minimization of the physical distances between students, professors, and tutors. They affirm that the development of modelling activities in VLEs adds complexity to the tasks proposed in the learning process, which helps students to develop their modelling abilities by using technological tools available in the Moodle platform. Thus, Brown (2015) argues that "technology assists the development of students' modelling abilities" (p. 432), especially those that are relevant to the elabora- tion of modelling projects in VLEs, such as forums and videoconferences.

This research was conducted by using a Moodle time-space continuum in a mathematics teacher education program; prospective teachers were accustomed to both collaborating across distances and a certain amount of freedom and autonomy. In this regard, the VLE environments shortened distance, established interaction and integration links, and also enabled dialogues and discussions in relation to the teaching and learning process without regards to the time/ space restriction of face-to-face instruction. Consequently, the main objective of this article is to propose mathematical modelling as a virtual learning environment.

\section{Developing Mathematical Modelling Process Using VLES}

The process of learning mathematics is related to the elaboration of mathematical concepts that helps students to construct mathematical knowledge by using their own contexts, culture, interests and motivation to learn. This approach develops students' autonomy because they learn how to elaborate their own strategies to solve problems they face in their daily life (D'Ambrosio, 2015).

In this context, Rosa and Orey (2016) argue that it is important to propose problems based on concepts that students previously elaborated and learnt in order to direct them towards observing, generalizing, structuring or destructuring the mathematical universe. Thus, a primary objective of this approach is to help students to understand and solve problems that emerge in everyday life. This approach allows modellers to experience mathematics in their lives and supports them in their search for explanations and different ways of reflecting and dealing with their own realities based on factual data they work with.

Consequently, this reflection becomes a transformative action that seeks to reduce the complexity of reality by choosing systems that represent it. It enables students to represent their own reality through the elaboration of mathematical models by developing techniques and strategies that assist them to explain, understand, comprehend, and critically reflect on these systems through the elaboration of mathematical modelling projects in Virtual Learning Environments. In this context, mathematical modelling as a learning environment is an interactive teaching alternative that focuses 
on active students' participation and collaboration (Freitas, 2016).

Conduction of the modelling process in Virtual Learning Environments is based on the three phases and 10 stages as proposed by Rosa (2000).

\section{Initial Phase: Modelling Preparation}

In this phase, through videoconferences, researchers met with both students and tutors to explain the dynamics of the mathematical modelling process. Students chose their themes and subsequently they elaborated justifications about their choice. Students were then directed to form working groups.

It is important to emphasize that there are three distinct mathematical modelling pedagogical practices that can be applied in the mathematics curriculum (Oliveira \& Barbosa 2013):

Case 1: Teachers choose a theme and then they describe it to the students. According to the content to be developed, teachers provide students with mathematical tools that are suitable to the elaboration of mathematical models to solve the proposed problem-situations. This approach integrates mathematical modelling to the processes of teaching and learning mathematics.

Case 2: Teachers choose a theme to the students and develop initial problems. Students investigate these problems through the development of data collection and the formulation of hypotheses and/or research questions in order to make necessary modifications to elaborate their models. The conduction of the proposed activities for the development of the modelling project is under students' responsibility. It is important that students are able to relate these activities to the problems they find in their own communities, contexts and/or realities.

Case 3: Students choose their own themes in which they have a particular interest and then they are encouraged to develop a modelling project. Students are responsible for all the stages of development of the modelling process. The role of the teachers is to mediate to enable students' social, critical, and reflective engagement during the development of the proposed activities.

Thus, teachers have to determine the curricular modelling configuration that enables students to develop their own pedagogical work in the classrooms. In the three cases above, teachers act as co-participants in students' research through a dialogic relationship about the projects they are developing during this process.

In this study, researchers have opted to work with Case 2. They present the transportation theme to the students to investigate it by applying the technological resources available in the Moodle platform. Then, in their groups, students discussed the transportation theme on the forums. In the next classes, each group of students collected qualitative and quantitative data by searching information on this theme in order to formulate the research question of their modelling projects.

Research on transportation was conducted on the internet, in virtual libraries, in the library of the distance educational centres $^{l}$, as well as in newspapers, magazines, and videos. Students posted the report of the research they developed to discuss it in the forums. They also watched a video-class about the modelling process that dealt with the elaboration of their projects and models. 
This phase includes stages: 1 - Choosing $a$ theme and 2 - Researching a theme.

\section{Intermediate Phase: Mathematical Model Development}

In this phase, in their groups, students reported about the characteristics of their modelling projects by informing the teachers what type of investigation they intended to address in their investigations. Students also indicated data sources and bibliographic references they used to conduct their research. As well, students collected in their groups necessary data on the theme they chose to study.

The groups recorded the main ideas when they read indicated material. Here, they learnt about the subject in various aspects and from different points of view. They learnt to develop their ideas in a clear, objective and organized way, limiting opinion to data-based observations, submit texts or chapters periodically for the analysis of the teachers, to verify citations and bibliographical references, to review the final text and to work towards developing a final report.

In this study, this phase was composed by three subphases and two stages each:

1) Research questions (3 - Elaboration of the research question and 4 - Formulation of mathematical problems).

2) Mathematical models (5 - Elaboration of mathematical models and 6 - Resolution of mathematical models).

3) Interpretation and comparison (7 - Interpretation of the solutions and 8 Comparison of the models with reality).

In this phase, teachers acted as coaches or facilitators of the modelling process by organizing lectures with professionals from various sectors, by assisting the groups of students in formulating, solving and analysing mathematical models, tables and graphs, and review the mathematical models presented.

\section{Final Phase: presentation of the final report}

This phase was completed on December $16^{\text {th }}, 2017$ with the presentation of the projects by the groups via videoconference. Previously, groups of students posted powerpoints and videos of their final report using a specific link on the platform. Before their presentations, students discussed in the forums some questions in relation to the preparation and presentation of their final reports.

By using videoconferences, researchers guided students to communicate correctly and positioning themselves to defend their projects. After presentations, face-to-face tutors at the educational centres, in which the defence took place, and members of a committee who participated in orientation sessions via videoconferences, evaluated students in their groups. This phase included two stages: 9 - Modelling Project Presentations and 10 - Evaluation.

\section{Methodological Framework Based on Case Study}

A literature review was developed in order to gather and base the work on information in regard to this study. Considering that distance education depends on tools and technologies that enable Virtual Learning Environments to be developed properly, the interactive technological tools available on the Moodle platform were also used. 
It is necessary to recognize that the use of and "development of technological tools generates more possibilities for using mathematical modelling in classrooms" (Gallegos \& Rivera, 2015, p. 443), which means that it is "possible to use digital tools in many phases of the modelling process" (Greefrath \& Rie $\beta, 2013$, p. 446).

Qualitative research is considered as an investigation process that allows for understanding based on diverse methodological traditions of inquiry towards the exploration of social and/or human problems. According to Creswell (1998), it is necessary that investigators are able to build holistic and complex pictures that enable them to analyse words, report detailed perceptions of informants, and conduct the study in natural settings (Creswell, 1998).

The methodological option used to collect, analyse, and interpret data gleaned from this study is of a qualitative nature since a dynamic relation was established between the real world and that of participants, which according to Creswell (1998) shows an inseparable link between the objective world and the subject's subjectivity that cannot always be translated into numbers.

Among the various approaches and qualitative methods available for the application in research about mathematics education, we have chosen the case study design. Case study is a form of qualitative research that analyses a situation, phenomena or specific problem with the objective to discover its essence in order to contribute to its overall comprehension (Yin, 1994).

According to Hopkins (2002), one important advantage of case studies is related to its importance in understanding a group's attitude and reaction to the process of teaching and learning school subjects.

\section{Institutional context and participants}

This study was performed at UFOP, during the second semester of 2017. The university offers long-distance education that is comprised of teacher education programs in geography, mathematics, and pedagogy, as well a bachelor degree in public administration. The Centro de Educação Aberta e a Distância $^{2}$ (CEAD) was created in 2000 and institutionalized in 2003. The long-distance teacher education program in mathematics was approved in 2005 and it was first offered in the second semester of 2007.

Data were collected from 76 students, in 5 (five) educational centres (polos) in the towns Barão de Cocais, Conselheiro Lafaiete, João Monlevade, and Lagamar in the state of Minas Gerais; and in the city of São José dos Campos in the state of São Paulo. Students who participated in this study were prospective mathematics teachers enrolled in the course: EAD512 - Seminar I: Mathematical Modelling. The curricular program of this course consists of both practical and theoretical mathematical content, which allows for the development and understanding of the modelling process in Virtual Learning Environments.

The conduction of the fieldwork of this study was developed in a Moodle platform. In accordance to the Universidade Aberta do Brasil (UAB) norms, students are assisted, in each educational centre (polo), by the professors of the course, and face-to-face and distance tutors. Hence, professors requested face-to-face tutors at each educational centre to organize students into working groups of 4 (four) or 5 (five) students in order to engage them to work with the transportation theme.

The VLE enabled the establishment of networks among groups of students from 
distinct educational centres without space or time boundaries and allowed them to exchange information in regard to the development of mathematical models during the elaboration of their projects. Thus, students in their groups were led through the mathematical modelling process and were requested to post evidence of their work on the Moodle platform.

\section{Research Design: Case Study}

A collective case study (Stake, 1995) was undertaken in five educational centres and their respective VLE (case). This qualitative research was a multi-site case study in which we explored five multiple bounded Moodle platforms over time through detailed data collection. This context involved "situating the case within each individual setting, which may be physical or the social, historical, and/or economic setting for the case" (Creswell, 1998, p. 61).

This research was also considered as an instrumental case study (Stake, 1995) because all five VLEs were used instrumentally to illustrate and promote an understanding of mathematical modelling as a virtual learning environment. This methodology allowed for an emerging design in which the research process was based on the data collected to critically reflect an increased understanding of the proposed case. The rationale for using a case study design in this investigation is that:

(...) The real business of case study is particularization, not generalization. We take a particular case and come to know it well, not primarily as to how it is different from others but what it is, what it does. There is emphasis on uniqueness, and that implies knowledge of others that the case is different from, but the first emphasis is on understanding the case itself. (Stake, 1995, p. 8)
According to this assertion, the main objective of this case study was to propose mathematical modelling as a virtual learning environment (VLE) by seeking an understanding of a particular discipline: EAD5 12 - Seminar I: Mathematical Modelling that is the unit-case of this study, which was offered in five educational centres through the Moodle platform. This methodological approach aimed to understand the main aspects of this unit-case, which was inserted in a specific context in order to highlight its identity and characteristics.

Case studies have been used in mathematics education to investigate issues related to student learning, teachers' professional practices, initial and continuing teacher education programs, and curricular innovation projects in order to enable investigators to understand the specificity of a phenomenon, which allows them to study the processes and dynamics of a given educational problem in order to develop pedagogical practices that contribute to its improvement.

\section{Stages of the Case Study}

According to Yin (1994), there are 5 (five) stages to delineate a case study: 1) formulation of a research question, 2) defining the case-unit, 3) data collection, 4) data analysis and results interpretation, and 5) report elaboration.

\section{a) Formulation of a Research Ques- tion}

The first stage in planning a case study begins with the formulation of the research question. Thus, the research must determine the answer to a question about a given situation, phenomenon, or problem. In this study, the research question was: How to develop mathematical modelling as a virtual learning environment? 
It is important to emphasize that the choice of the case as a research design of this study was motivated by research questions that were answered through the conduction of the fieldwork by applying diverse data gathering methods, which enabled the production of evidence toward a clearer understanding of this case.

\section{b) Defining the Case-Unit}

This stage is consistent with the delimitation of the unit that constitutes the case investigated by the researchers in this study. Thus, in defining the case-unit, the criteria for the selection of case studies are established. This means that the number of cases should be defined whether the study addresses one or multiple cases, as well the delimitation of when and where the case will be observed. As stated previously, the unit-case defined for this study was the discipline EAD512 - Seminar I: Mathematical Modelling.

In September 2017, a survey was conducted with 20 federal universities in the states of Bahia, Minas Gerais, and São Paulo to verify the offering of distance teacher education courses in mathematics. As well, the survey sought to see if these courses also offered mathematical modelling courses in their curricular matrix. These states were selected because UFOP offers distance courses at educational centres in these respective locations.

The results of this survey showed that 13 federal universities in these states do not offer distance teacher education courses in mathematics and that only $2(28.6 \%)$ universities out of $7(100 \%)$ that offer distance teacher education courses in mathematics also offer mathematical modelling course as a discipline. The particularities presented in this case study enabled the researchers to collect necessary data and relevant information in order to broaden their understanding of this study by presenting a complete description of the phenomenon investigated in this context.

\section{c) Data Collection}

There is a plurality of data collection procedures to obtain information in regard to a case to be studied. Diverse sources of data were collected, which allowed the development of a holistic understanding that included a thick description of the reality of this research. The data collection was performed in the fieldwork by using several instruments and qualitative procedures such as observation, modelling activities and projects, document analysis, and questionnaire applications with open-ended questions.

The data obtained through these instruments guaranteed the quality of the results, which enable the development of its validity through a triangulation process. Qualitative data were collected through the following collection instruments: initial and final questionnaires, mathematical modelling projects, discussion forums on the VLE, activities in the VLE, and field notes.

\section{Initial and Final Questionnaires}

Both initial and final questionnaires were applied via the Moodle platform and were posted in a specific link in the VLE. The main objective of the initial questionnaire was to draw a profile of the students, since it contained questions related to their identification, social, and academic condition.

It also had questions related to the students' knowledge about the modelling pro- 
cess developed in this course. The main objective of the final questionnaire was to verify students understanding of the process of model elaboration during the development of modelling projects in the VLE.

\section{Mathematical Modelling Projects}

Modelling projects started from a problem chosen by the students to determine its answer through the elaboration of mathematical models. This approach enabled students to develop models in accordance with their own interests. In these projects, experiments with the proposed curricular contents were conducted, as well visits to colleges, universities, companies, museums, public agencies, offices, and cooperatives in order to help students to collect data and information in relation to the transportation theme.

At the end of their projects, groups of students presented the results of their research to the researchers and the members of the other groups, who collaborated with suggestions to improve their modelling process. As well, the members of each group of students prepared a final report, which included their proposed research question, the development of modelling activities related to the elaboration of their models, including their solutions and conclusions.

\section{Discussion Forums}

Discussion forums enabled students to exchange ideas, post messages, and elaborate and answer questions from colleagues, tutors (both face-to-face and distance). As well, tutors kept abreast of the activities and tasks proposed in the VLE. According to Kanuka and Anderson (1998), because forums allow students to access the VLE according to their own needs by dispensing the simultaneous participation of professors and tutors, these tools are available via Moodle provided asynchronous communication.

The discussion forums were elaborated in order to verify student queries, difficulties, and questions that arose during the activities proposed in the VLE. For example, one student affirmed that the "use of discussion forums facilitated the learning of mathematical contents during the development of the modelling process related to transportation". This approach enabled students to exchange information between the researchers and tutors in relation to the elaboration of their modelling projects and mathematical models.

\section{Modelling Activities}

The first sources of information considered as data collection instruments are the educational institution's own records in the form of documents, records, reports, and computer files of the activities posted on the VLE. In this regard, Leedy and Ormrod (2001) argue that documentary records are papers and documents that provide information to help researchers to make and communicate decisions and record topics of interest to the educational institution and the students.

In the VLE, mathematical modelling activities are proposed to the students in the Moodle platform that contain a range of diverse tasks related to the theme, in this case, transportation. In this regard, "technology assists the development of students' modelling abilities" (Brown, 2015, p. 432) that are central to the elaboration of modelling projects. According to Gallegos \& Rivera (2015), it is important to acknowledge that "modelling activities are being used to along with technological devices in order to promote increased understanding based on this strategy" (p. 443). 


\section{Field Notes}

This instrument is composed of information obtained from observations made during data collection processes that occurred in the VLE, which were related to the elaboration and conduction of the activities and tasks proposed in the modelling projects on the platform. As well, the participation of the students in the discussion forums and videoconferences available in the VLE were vital and obligatory.

During the accomplishment of the proposed modelling activities in the VLE, the researchers took notes about observational behaviour of the students in their groups related to the discussions that occurred in the forums, in regards to the questions posed, which contained important information about transportation, which assisted them to develop data analysis and interpretation of results of this study.

\section{d) Data Analysis and Results Inter- pretation}

Data analysis of this study was conducted by using the examination, codification, tabulation, and categorization of the evidence that instructed the initial premises of the study (Yin, 1994). With the achievement of this systematization process, researchers reflected on the information enclosed in the data, which enabled them to interpret the results obtained in this analytical process. This approach allowed the researches to develop a response to the research question that was formulated in accordance to the problem statement developed for this research.

For the achievement of the analytical and interpretative processes developed in this study, the codification and categorization of the qualitative data were conducted through the identification of codes by counting of words, terms, phrases, and expressions and then along with the elaboration of categories by arranging these codes according to their own characteristics. The main objective of these processes was related to data reduction that revealed important features of information analysed through the categorization of the codes into categories with the same theoretical conceptualization.

\section{Methodological Procedures}

The conduction of this study was bounded by time and place since each virtual learning environment was studied consecutively over a semester. It occurred only in the Moodle platform of EAD512, via the five educational centres, which hosted the students for the development of the modelling projects. According to Rosa and Orey (2018), "curricular program of this course is comprised of both theoretical and practical mathematical content that enabled the development of the modelling process in this environment" (p. 11).

This research was conducted from August $7^{\text {th }}, 2017$ to December $22^{\text {nd }}, 2017$. First, the discipline was elaborated, prepared, and posted on the Moodle platform. Important information in regard to the development of the model had been available to the students in the VLE.

The syllabus that contained the description of the course was posted on the Moodle platform with the terms of the proposed tasks. A calendar with the dates and times of synchronous activities were published on the VLE as well. There were tasks and activities available every week in this environment to be worked on by the students and then to be sent to the tutors and researchers through specific links inserted on the Moodle platform. 
In the VLE, synchronous classes were held and asynchronous modelling activities were posted in the Moodle platform. According to Borba (2012), it is necessary to combine synchronous with asynchronous tasks to accomplish activities posted on the VLE. Hence, short mathematical modelling video lessons were made available in the VLE and instruction about the development of the modelling projects were transmitted via video conferences.

Researchers organized lessons and elaborated modelling activities and projects that were posted on the VLE. They also developed discussion forums that allowed the preparation of the students for the development of their modelling projects. Four synchronous meetings were held during the course, which enabled the development of discussions in relation to the mathematical models elaborated by each group of students.

The course was assembled by the researchers on the Moodle platform through the elaboration of activity blocks that demonstrated the connection between the three phases and the ten stages of the development of the mathematical modelling process (Rosa, 2000). Table 01 shows the activities bocks posted in the VLE and its relation to the three phases and ten stages of the development of mathematical modelling process.

Table 01: Activities blocks of mathematical modelling in the VLE

\begin{tabular}{|c|c|c|}
\hline Modelling Phases & Period & Modelling Steps \\
\hline Block 1: Initial Phase & From August $7^{\text {th }}, 2017$ to & 1) Choosing a theme \\
\hline Modelling & September $16^{\text {th }}, 2017$ & 2) Research about the theme \\
\hline Preparation & & \\
\hline \multirow{10}{*}{$\begin{array}{l}\text { Block 2: Intermediate } \\
\text { Phase } \\
\text { Modelling Project Devel- } \\
\text { opment }\end{array}$} & \multirow{10}{*}{$\begin{array}{l}\text { From September } 18^{\text {th }} \text {, } \\
2017 \text { to October } 28 \text { th, } \\
2016\end{array}$} & Subphase 1: Research questions \\
\hline & & 3) Elaboration of the research question \\
\hline & & 4) Formulation of mathematical prob- \\
\hline & & lems \\
\hline & & Subphase 2: Mathematical Models \\
\hline & & 5) Elaboration of mathematical models \\
\hline & & 6) Resolution of mathematical models \\
\hline & & $\begin{array}{l}\text { Subphase 3: Interpretation and Com- } \\
\text { parison }\end{array}$ \\
\hline & & 7) Interpretation of the solutions \\
\hline & & $\begin{array}{l}\text { 8) Comparison of the model with re- } \\
\text { ality }\end{array}$ \\
\hline Block 3: Final Phase & From October $30^{\text {th }}, 2016$ & Modelling Project Presentation \\
\hline $\begin{array}{l}\text { Presentation of the Final } \\
\text { Report }\end{array}$ & to December 22 $2^{\text {nd }}, 2017$ & 10) Evaluation \\
\hline
\end{tabular}

Source: Adapted from Rosa and Orey (2018) 
In this course, in order to determine the research question (subphase 1), students discussed their ideas in the forums, with the accompaniment and supervisions of the researchers and tutors, the research questions they wanted to formulate, as well the formulation of the mathematical problems. Then, students reported their findings in relation to the chosen research questions by posting their reports in the VLE in order to share it with other classmates in the Moodle platform.

Then, students posted on the VLE a reflective essay that explained the difficulties and strengths they had during the development of their modelling projects. As well, they discussed questions and observations about the mathematical content needed for the elaboration of their models (subphase 2) by using digital tools, which helped them to understand, comprehend, and translate their problems into mathematical language.

Afterwards, students posted a report on the VLE on the mathematical models they developed. The use of "digital tools not only broadens the range of approaches that can be taken to solve certain mathematical models, but also the types of situations that can be investigated by providing the possibility of using solution strategies, which would not be accessible otherwise" (Greefrath \& Rie $\beta$, 2013, p. 445/446).

In the following classes, students discussed in the forums about the process of solving their mathematical models and they also participated in videoconferences to discuss about the solution of their models, as well about the elaboration of their projects. These videoconferences were conducted at the university with the students' participation in their educational centres. Then, students discussed on the forums about their ideas related to the interpretation of the solutions of their models and their comparison (subphase 3 ) with the reality they observed.

Students also posted a reflective text on the Moodle platform in relation to these two topics. Posteriorly, they posted on the VLE their revised models after both their colleagues and the researchers made and shared comments and recommendations. Then, they discussed with the researchers and tutors the revisions addressed in their mathematical models.

We highlight that the modelling activities proposed in these blocks were related to the elaboration of mathematical models and modelling projects, which were discussed in the forums and videoconferences. These tasks were elaborated according to the steps proposed in the methodology of case study and posted via specific links on the platform. Students also participated in the discussion forums, as well by posting reports and group reflection texts related to the elaboration of modelling projects including the models about transportation developed in the VLE.

In this study, discussion forums were used to enable students to discuss their models and projects. As well, during the accomplishment of the tasks and the execution of the mathematical modelling projects by the students, researchers registered their observations in their field notes. These observations were made via Moodle and videoconferences.

\section{Results and Discussions}

Interpretation of the results obtained from the data analysis helped researchers to elaborate categories that emerged from qualitative data collected during the accomplishment of the fieldwork of this study. Theoret- 
ical basis discussed in the literature review was also an important reference for the interpretation of the information contained in the data collected. Thus, an important category that emerged from the data analysis was Mathematical Modelling in the VLE.

\section{Mathematical Modelling in the VLE}

Technological resources available in the VLEs foster interaction among teaching materials, teachers, students, and tutors during the development of the modelling process in the Moodle platform. These resources help educators to organize and schedule a range of learning modelling activities as a means to make them available to the students rather than just manage mathematical content (Rosa \& Orey, 2016).

These environments provided resources that enabled students, teachers, and tutors to participate in several online learning interactions. They are technological tools in education that enable modifications in the mathematics curriculum (Silva, Costa, Rogerson, $\&$ Prior, 2007). Thus, they are capable of exploring social situations in order to develop distinct and diverse behaviour responses for variety of different simulated social interactions (Kerr, Neale, \& Cobb, 2002).

Since it can enhance students' learning experiences by including internet and computers in the mathematical modelling process, these environments have many assets and benefits that support their progression in the mathematical modelling course. Therefore, students need to participate in a VLE that enable them to debate potential real-world situations and problems suitable to be solved by applying these technological resources. It allows them to develop mathematical solutions collaboratively in order to exchange information about problems and phenomena in which they are not co-located in the same context (Meletiou-Maurotheris, 2012).

The combination of modelling with Virtual Learning Environments provides the development of independent and autonomous students because it enables them to investigate their research questions in an interactive, cooperative, and collaborative way by sharing information and inquiries in order to exchange information with their peers, teachers, and tutors in the video conferences and discussion forums.

For example, one of the students stated that the "virtual learning environment helps us to share information because mathematical models are discussed through the exchanging of information, materials, and suggestions that occur in the discussion forums". Another student argued that "modelling activities with transportation developed in the Moodle platform assisted us, in our groups, in determining different ways to apply mathematical content to our daily lives in a critical and reflective manner".

In this study, mathematical modelling was proposed as a virtual learning environment that facilitated the development of reflection of students through the elaboration of their modelling projects that enabled them to critically demonstrate pedagogical applicability of their mathematical models. In the study of the problem situations faced in the daily life it is necessary state that the use of technological tools available in the Moodle platform was vital.

In this case study, students were invited to investigate situations of their own reality by using technological resources (via internet) in order to obtain mathematical representations of the problems they face in 
their daily lives (in this case transportation problems) through the elaboration of mathematical models. For example, one student commented about the modelling process in a virtual learning environment that:

(...) It serves our town. By first our group identified a problem related to transportation we are facing in our own communities in relation to the decrease of number of buses that using technological tools available in the VLE we were able to develop mathematical models by associating them to the mathematical content we are learning in our course.

Technological resources such as video lessons, hand-outs, graphics, and activities available on the VLE helped students to work collaboratively and increase their interactions with the modelling activities. In this context, one student affirmed that "these tools enabled us to exchange ideas, post messages, and elaborate and answer questions from colleagues, professors, and tutors by using asynchronous communication such as forums". Likewise, another student stated that "these technological resources helped us to focus on our questions, which allowed us to elaborate our models interactively and collaboratively by solving modelling activities proposed in the Moodle platform".

As it refutes the traditionalist approach of the teaching and learning process in mathematics in teacher education programs, the VLE allowed for the reorganization of mathematical content and its link to the reality of the students. In this context, the use of technological resources available in this environment helped students to understand, analyse, and interpret mathematical models proposed in the Moodle platform. This approach helped students to acquire competencies for the development of their citizenship in responsible and critical ways. In this context, one of the students stated that:
(...) The development of mathematical modelling in the virtual learning environment helped me to associate information developed in diverse contexts, such as the rise in transportation costs, which contributed to the development of my critical and reflective thinking. Even if we may not be able to solve the problem related to bus transportation in our town, we certainly can be aware of the need to understand it in order to find a reasonable solution to solve it.

Similarly, the participation of students in a videoconference propitiated a discussion in regards to the transportation problem related to the increasing of bus tickets. For example, one of the students affirmed that:

(...) Mathematical concepts contribute to the development of reflection on the problems we face daily in order to determine its possible solutions. Thus, the critical analysis of the information in the collected data may change our posture in regards to our academic and citizenship development.

Therefore, active, interactive, cooperative, and collaborative participation using technological resources available in the VLE was important for the development of critical reflections on the transportation issue and other societal problems facing Brazilian contemporary society.

In this regard, Rosa and Orey (2018) state that VLE allows the development of the flexibility of the modelling process, which is associated with the research and problematization necessary for the elaboration of questions, whose objective is the selection, organization, manipulation, criticism and reflection on these problems. For example, one student replied in a videoconference that the "modelling process was related to the conduction of research about real-world issues like transportation that occur every 
day in our lives" and that the contributions that come from VLE are related to the "conversations with colleagues in the discussion forums available on the platform in regards to transportation".

This environment encouraged students to interact in an active way because it enabled them to develop relevant discussions related to transportation theme that helped them to develop their modelling projects and mathematical models. Hence, one student affirmed that "tasks and activities proposed on the VLE were easily developed due to interaction, collaboration, and help of the professors and tutors who commented on our assignments in the forums",

Another student commented that "this environment enabled us to establish networks between tutors and professors, which allowed us to exchange information related to the development of our mathematical models" while a group of students wrote that "we elaborated our mathematical models in a collaborative way that engaged us in a process of exchanging experiences in regards to the discussion related to transportation problems we face daily".

This interactive, cooperative, and collaborative participation of the prospective teachers in the VLE is important for the development of their critical reflection on the problems faced by society through the elaboration of mathematical models and modelling projects (Rosa \& Orey 2016). For example, in their projects, students in one of the groups stated that "transportation issues are especially critical in large cities in which there is an acceleration of demo- graphic and industrial growth that have not been followed by suitable public policies to control traffic congestion and to implement satisfactory parking infrastructure".

On the other hand, about the results of the mathematical model developed in their modelling project, students in another group discussed that "the bus ticket price is not fair and the quality of transportation needs to be improved". In this context, a group of students in one educational centre decided to problematize an issue about public transportation in their town in relation to the price of a bus ticket.

Thus, students posed in the forum the following research question: "What is a fair price for a bus ticket in our town if we consider the per capita income of its population?" In order to be able to answer this question, these students interviewed people and public officers in their town to obtain information to solve this problem.

In accordance to the results of the interviews posted and discussed in the forums, the students found that, approximately, 35\% of the population in their town allocates $8 \%$ of their per capita income with expenses related to public transportation. They also found that public transportation is used for people four times a day in their town, mainly to get to work, approximately, 24 days a month, except Saturdays and Sundays.

Then, in a videoconference, these students with their tutors and professors discussed the elaboration of their mathematical model. Posteriorly, they determined the following mathematical model through discussions developed in the forums:

$$
\mathrm{T}=\frac{\text { PCI } x}{\mathrm{~N}} \quad \begin{aligned}
& \mathrm{T}=\text { bus ticket } \\
& \mathrm{PCI}=\text { per capita income } \\
& \mathrm{E}=\text { expenses with public transportation } \\
& \mathrm{N}=\text { number of tickets }
\end{aligned}
$$


During the discussions in the forums, the students began the development of their mathematical models. In their data collection, they also found that "the cost of the bus ticket in our town is $\mathrm{R} \$ 2,70^{3}$ and that the "per capita income of the population is 3,1 minimum salaries, which is $\mathrm{R} \$ 937,00^{4}$. Thus, we determined that $3,1 \times 937,00=$ $2.904,70$ ". By applying their mathematical model they found that:

$$
\mathrm{T}=\frac{2.904,70 \times 0,08}{96}=\frac{232,376}{96}=2,42
$$

By analysing their model, students concluded that the "bus ticket fare was not suitable to the per capita income of the population in our town". They also argued that "even though the charged price of the bus ticket was R 0,28 more expensive than the one determined by our model this does not guarantee the quality of the transportation service available to the population in our town". After analysing their mathematical model, these students also affirmed that:

(...) Mathematical concepts contributed to the development of reflection on the problems we face daily in order to determine its possible solutions for transportation problems. Thus, the critical analysis of the information in the collected data helps to change our posture in regard to our academic and citizenship development.

In this context, mathematical modelling projects can be considered pedagogical alternatives that enable students to assimilate what they know to a problem and situations faced daily through the use of a method that organizes the elaboration of mathematical models. Therefore, these projects aim at transforming the teaching and learning process by modifying the basis of the organization of the school mathematics curriculum. In this regard, one group of students concluded in their modelling project that:

The virtual learning environment allowed us to access modelling activities in accordance to our own needs. This approach helped us to develop our modelling abilities because we looked for different ways to solve problems we encounter daily by applying technological tools in the Moodle platform. In this configuration we were able to access resources such as modelling activities, forums, videoconferences, course information, and additional links to digital readings in order to organize their study more effectively. Hence, synchronous and asynchronous technological resources available provided students with opportunities to develop their modelling activities at the time and place of their own choice, which gave them control of their own learning. The asynchronicity in online communication provides students time to reflect and think about the activities and responses they posted on the VLE.

As well, this environment has the advantage of starting from a problem situation that directly involves students to guide them in determining a response or solution to a given problem or situation, through the elaboration of a mathematical model by means of dialogue and peer interaction.

The results of this study show the possibilities of considering mathematical mod- 
elling as a virtual learning environment that enables: a) the integration of students, tutors, and professors to deliver comments, messages, and encouragement; b) the conduction of pedagogical supervising and monitoring such as sending messages to the students in regard to their participation in the discussion forums and about their performance in the resolution of modelling activities; and c) the provision of technical support such as facilitating students and tutors access to their achievement reports available in the Moodle platform.

\section{Final Remarks}

Working with themes in the VLE by through developing mathematical models and elaborating modelling projects enabled students to critically reflect on the importance and the role of mathematics in their own contexts. Through the development of the modelling projects, the researchers inferred that VLE allows for continuous updates in the course content; in the development of video conferences and discussion forums concerning teaching practices in regard to the modelling activities, and the formulation of questions about the pedagogical and technical aspects in regard to the development of their modelling projects.

In this process, synchronous technologies such videoconferences, audio conferencing, and chats required simultaneous participation of the professors, tutors, and students at different locations at the same time and it was accomplished in real-time. Asynchronous technologies such as electronic mail, discussion groups, forums, electronic bulletin boards, interactive tutorials, and evaluations did not require simultaneous participation of the professors, tutors, and students because they were delivered on-demand and referred to learning situa- tions that did not occur in real-time.

The lessons were transmitted to all educational centers through videoconferences. In this context, a combination of synchronous and asynchronous timing and recording technologies of the VLE allowed students to both have access to and time to listen to their classmates, tutors, and professors' postings about their mathematical models and modelling projects. On an average of once a week, there were activities and tasks to be performed by the students and to be sent to tutors and professors by using specific links available in the VLE.

This approach enabled students to discuss real-world problems interactively, cooperatively, and collaboratively through the elaboration of mathematical models by exchanging information in their educational centres, as well on the Moodle platform. For example, in the forums, students debated about mathematical content needed for the elaboration of their models. Thus, technological tools such as videoconferences, forums, and video lessons available to them were used as means for the development of their investigation and allowed them to share mathematical content in relation of the development of communication, collaboration, and interaction between students, tutors, and professors.

During the development of this study, students were encouraged to actively interact in the VLE in order to enable the development of relevant discussions on the transportation theme for the development of their mathematical models and modelling projects. Thus, this study highlighted pedagogical, practical, and strategic issues in using VLE for the development of mathematical modelling projects through interactive mathematics teaching and learning in 
order to meet the educational needs of the prospective teachers.

Therefore, it is important to propose mathematical modelling as a virtual learning environment in teacher education programs in mathematics because students are invited to inquire and investigate their chosen theme in accordance to their own interests and reality. VLE enabled the development of discussions forums that allowed prospective teachers to clarify questions in regard to modelling tasks, the development of models, and the elaboration of their final projects.

The critical and reflective attitude of students involved in the proposed theme helped them in the development of mathematical models related to these issues as well provided a reflective analysis of the nature of these models and their role in society. For example, the results of this study show that the development of modelling projects allowed students to reflect on the importance of mathematics in their daily life through the conduction of their investigative work in the process of solving mathematical models. Thus, students were able to reflect on the transportation problems they face daily when they develop their mathematical models by using technological tools available in the Moodle platform.

After the problem was formulated, technological tools in the VLE were used to enable them to gather information in regard to their theme through the development of modelling projects. This approach helped our students to problematize, contextualize, and investigate their chosen themes developed in their projects.

As well, they elaborated their research questions that aimed to collect, select, organize, and handle the information that al- lowed them to critically reflect in solving everyday problems. Students learned that, in order to form an opinion, it is best to look at and discuss the collected data. This is an important feature of mathematical modelling since it provides conditions for students to understand how to solve problems learners face by enabling them to develop critical and reflective discussions about the role of mathematics in society

The Virtual Learning Environments helped the students to organize and represent collected data as well as to fit the information in different ways by using distinct representations to determine possible solutions. It favoured the development of students' criticality and reflection on the elaboration of modelling projects that help them to apply models to the study and discuss problems they face in their lives (Rosa \& Orey, 2016). It also contributes to the development of collaborative experiences among researchers, students, and tutors through interactions provided by the technological resources available in the Moodle platform.

In accordance to this context, this environment allowed learning to occur through socialization because knowledge is better constructed when the students work in groups and act cooperatively in order to support and encourage each other. Thus, there is a need to provide mechanisms that foster the development of student citizenship by enabling them to position themselves critically, responsibly and constructively in different social situation, both economically and politically.

For example, the results of this study also showed that, in the forums, students were required to share their responses to the reading assignments and interact with each other, as well with tutors and profes- 
sors. Technological resources available in the VLE such as forums assisted them in the organization of the modelling activities, the elaboration of their modelling projects and mathematical models. Students' interest on the transportation theme enabled them to construct mathematical models that were discussed and negotiated in the forums in a collaborative way.

Hence, engaging learners in open-ended questions, with support and questionings gave our prospective teachers, in the mathematics teacher education program, an experience that many said they would take to their pupils. In a time of great political and environmental upheaval, it was good to assist learners to understand pedagogical tools that allowed them to look at controversial theme and develop powerful mathematical models that might be used to solve problems in the communities and in the lives of the students.

\section{Notes}

1. Distance educational centres are extensions of the university, which are maintained in collaboration with local governments. The centres are equipped with a library, computer labs and internet; as well they provide tutorial assistance to the students. In many localities, these educational centres have become the lone access or the internet and the first public library resources.

2. The Open and Distance Educational Centre.

3. $\mathrm{R} \$$ is the symbol for the Brazilian official currency named Real.

4. In $2017, \mathrm{U} \$ 1,00=\mathrm{R} \$ 3,20$

\section{REFERENCES}

Barbosa, J. C. (2006). Mathematical modelling in classroom: a critical and discursive perspective. ZDM, 38(3), 293-301.

Borba, M. (2005). Humans-with-media: transforming communication in the classroom. In A. Chronaki \& I. M. Christiansen (Eds.), Challenging perspectives on mathematics classroom communication (pp. 51-77). Greenwich, CT: Information Age.

Borba, M. C. (2012). Humans-with-media and continuing education for mathematics teachers in online environments. $Z D M, 44(6), 801-814$.

Brown, J. P. (2015). Visualisation tactics form solving real world tasks. In G. A Stillman, W. Blum, \& Biembengut, M. S. (Eds.). Mathematical modelling in education research and practice: cultural, social and cognitive influences (pp. 431-442). New York, NY: Springer. 
Creswell, J. W. (1998). Qualitative inquiry and research design: choosing among five traditions. London, England: Sage.

D'Ambrosio, U. (2015). Mathematical modelling as a strategy for building-up systems of knowledge in different cultural environments. In: G. A. Stillman, Blum, W. Blum, M. S. Biembengut (Eds.). Mathematical modelling in education research and practice: cultural, social and cognitive influences (pp. 35-44). New York, NY: Springer.

Freitas, J. F. R. B. F. (2016) Modelagem matemática no ambiente virtual de aprendizagem (AVA): entendendo as suas dimensões crítica e reflexiva a partir de um estudo de caso. Dissertação de Mestrado Profissional em Educação Matemática. Departamento de Matemática. Ouro Preto, MG: Universidade Federal de Ouro Preto.

Gallegos, R. R., \& Rivera, S. Q. (2015). Developing modelling competencies through the use of technology. In G. A Stillman, W. Blum, \& Biembengut, M. S. (Eds.), Mathematical modelling in education research and practice: cultural, social and cognitive influences (pp. 443-452). New York, NY: Springer.

Greefrath, G., \& Rie $\beta$, M. (2013). Reality based test tasks with digital tools at lower secondary. In G. A. Stillman; G. Kaiser; Blum, W.; \& J. P. Brown (Eds.), Teaching mathematical modelling: connecting to research and practice (pp. 445-456). New York, NY: Springer.

Hopkins, D. (2002). A teacher's guide to classroom research. Maidenhead, England: Open University Press.

Kaiser, G., \& Sriraman, B. (2006). A global survey of international perspectives on modelling in mathematics education. ZDM, 38(3), 302-310.

Kanuka, H., \& Anderson, T. (1998). On-line social interchange, discord, and knowledge construction. Journal of Distance Education, 13(1), 57-74.

Kerr, S. J., Neale, H. R., \& Cobb, S. V. (2002), Virtual environments for social skills training: the importance of scaffolding in practice. Proceedings of the Fifth International ACM SIGCAPH Conference on Assistive Technologies (pp. 104-110) New York, NY: ACM Press.

Leedy, P., \& Ormrod, J. (2001). Practical research: planning and design. Upper Saddle River, NJ: Merrill Prentice Hall. Thousand Oaks: SAGE Publications.

López Dávila, C. E. L. (2015). Un modelo de investigación orientado a la implementación de programas estructurados en ambientes virtuales de aprendizaje. Uni-pluriversidad, 15(2), 61-73.

Meletiou-Maurotheris, M. (2012). Online communities of practice as vehicle for teacher professional development. In: J. A. Angel, M. A. Huertas, S. Trenholm, \& C. Steegmann (Eds.), Teaching mathematics online: emergent technologies and methodologies. Hershey, PA: IGI Global.

Oliveira, A. M. P., \& Barbosa, J. C. (2013). Mathematical modelling, mathematical content, and tensions in discourses. In G. A. Stillman; G. Kaiser; Blum, W.; \& J. P. Brown (Eds.), Teaching mathematical modelling: connecting to research and practice (pp. 67-78). New York, NY: Springer. 
Rosa, M. (2000). From reality to mathematical modelling: a proposal for using ethnomathematical knowledge. College of Education. Sacramento, CA: California State University, Sacramento (CSUS).

Rosa, M., \& Orey, D. C. (2012). A modelagem como um ambiente de aprendizagem para a conversão do conhecimento matemático. BOLEMA, 26(41A), 261-290.

Rosa, M., \& Orey, D. C. (2016). Developing mathematical modelling in Virtual Learning Environments by applying critical and reflective dimensions. In: Wallace, K. (Org.). Learning environments: emerging theories, applications and future directions (pp. 1-20). New York, NY: Nova Science Publishers.

Rosa, M., \& Orey, D. C. (2018). Developing a mathematical modelling course in a virtual learning environment. $Z D M$, 50(1-2), 173-185.

Silva, N., Costa, G. J. M., Rogerson, S., \& Prior, M. (2007). Knowledge or content? The philosophical boundaries in e-learning pedagogical theories: research, reflections and innovations in integrating ICT in education. London, England: Routledge.

Stake, R. (1995). The art of case study research. Thousand Oaks, CA: Sage Publications.

Yin, R. K. (1994). Case study research: design and methods. Newbury Park, CA: Sage Publications. 